\title{
Reversal of the glabellar reflex in Parkinsonism by L-dopa
}

\author{
HAROLD L. KLAWANS, JR. AND JAMES A. GOODWIN \\ From the Department of Neurology, Presbyterian-St. Luke's Hospital, Chicago, \\ Illinois, U.S.A.
}

The glabellar reflex was first described in 1896 by Overend. Since then many names have been applied to this phenomenon, which is characterized by blinking of the eyes in response to various stimuli applied to the face and cranium.

Wartenberg (1945) in a review of the subject described the reflex as myotatic in nature and professed that the best way to elicit it consisted of grasping the outer canthus of the eye with thumb and forefinger and then applying a slight blow to the examiner's fingers with a reflex hammer. The stimulus from which the reflex gains its name, however, is a light tap to the glabella.

In normal persons, when the tap frequency is held constant, the blinking stops after the first few taps. In certain patients the reflex blinks continue in response to each glabellar tap for an indefinite period. This is considered clinically to represent the abnormally exaggerated glabellar response.

Delineation of this reflex remained clinical until Kugelberg (1952) conducted an EMG study which characterized the response as a dual one. In his patients a tap to the glabella produced a double response as measured by a recording electrode in the orbicularis oculi muscle. The characteristics of the first response correspond with those of a monosynaptic, myotatic reflex, while the features of the second component are those of a multisynaptic, nociceptive type reflex. The afferent limb of both components involves the trigeminal nerve, since trigeminal rhizotomy abolishes both components; the central connections are as yet unknown.

According to Wartenberg (1945) the clinical usefulness of the glabellar reflex consists of diminution of response on the side of a peripheral facial palsy with preservation of bilateral response or exaggeration in the case of central facial palsy. The almost constant presence of an exaggerated response in cases of postencephalitic Parkinsonism led Wartenberg (1945) to state that the glabellar reflex is pathognomonic of this disease. This concept remained unchallenged until the series of Pearce,
Aziz, and Gallagher (1968) in which the occurrence of exaggerated glabellar response was described in relation to various intracranial diseases apart from Parkinsonism. Wartenberg's (1945) conception was supported by their finding of positive glabellar response in 19 of 20 patients with proven Parkinson's disease. They exploded the concept of the reflex's specificity, however, by describing its presence in 15 of 56 patients with intracranial diseases other than Parkinsonism. Of these 15 patients, only five had one or more features of Parkinson's disease (masked facies, resting tremor, rigidity, simian posture). The most outstanding pathological feature of those non-Parkinsonians with positive glabellar response was widespread bilateral cerebral destruction as in Alzheimer's disease and other presenile and senile dementias, as well as in widespread intracranial neoplasms.

The anatomical locus from which accentuation of the glabellar response emanates is not established and the reflex can no longer be considered pathognomonic of Parkinson's disease-post-encephalitic, or idiopathic.

Most observers consider the exaggerated glabellar response to be a release phenomenon. This implies that involvement of an inhibitory pathway by a pathological process has 'released' a reflex which is normally suppressed. This released reflex would then fall within the category of the positive phenomena seen in Parkinsonism.

Pearce et al.'s (1968) finding of diffuse cerebral disease in their patients with the exaggerated glabellar reflex agrees with Denny-Brown's (1956) concept that the release originates from disturbance of frontal lobe function. Pearce et al. (1968) are, however, unwilling to consider the enhanced glabellar response of Parkinson's disease as a release of function. Rather, they ascribe this phenomenon to "enhanced proprioceptive and avoiding responses seen in basal ganglia disease.'

In the course of treating Parkinsonian patients with L-dopa we observed that in certain instances 
the glabellar response reverted to a normal nonsustained blinking. It is the purpose of this paper to report these findings and make some inferences as to the meaning of this reversal in terms of pathogenesis of the sustained glabellar response in Parkinson's disease.

\section{MATERIALS AND METHODS}

This study includes 16 patients with known Parkinsonism in whom the glabellar sign was elicited on initial examination. Since attempts to elicit this sign were not made in all patients seen with Parkinsonism, not all patients treated with L-dopa at this hospital are included in this report. No conclusions as to the frequency of a positive glabellar sign in Parkinsonism can be drawn from our data. Also, the present series is not intended to demonstrate the overall effectiveness and safety of L-dopa.

All patients were treated with L-dopa beginning with small doses and reaching maximal doses of 3 to $7 \mathrm{~g}$ per day. All patients were receiving $L$-dopa for at least three months before the judgment was made as to whether the glabellar sign persisted. The glabellar response was considered absent only when a sustained blinking reflex could not be elicited on two separate occasions.

The sign was always evoked with light taps to the glabella by the examiner's index finger. The examiner's arm and hand were held above the patient's head outside his field of vision in order to eliminate startle responses from the observations.

The response to L-dopa therapy was graded as good, fair, or minimal. Response was considered good if a patient improved at least one stage, fair if there were definite improvement but no change in the overall stage of disease, and minimal if there were evidence of improved function which was not great enough to expand the patient's ability to carry out the activities of daily living. Some response was shown by all patients in this series.

\section{RESULTS}

The glabellar reflex reverted to an unsustained blinking in eight of 16 patients during the administration of L-dopa. Table $I$ is a summary of all patients in the series relating reversal of the glabellar sign to other aspects of their illness.

Table II, III, and IV compare reversal of the reflex abnormality with stage of disease, duration of illness, and clinical response to L-dopa respectively. The stage of Parkinsonism was graded according to the scheme of Hoehn and Yahr (1967). It is of note that, among nine patients in stage III, seven or $78 \%$ demonstrated reversal of the glabellar reflex. In the three stage IV patients reversal occurred in only one patient, and in four stage $\mathrm{V}$ patients there were no reversals. Similarly, $70 \%$ reversal occurred in patients who had had Parkinson's disease for less than 10 years compared with only $16.7 \%$ reversal in those with duration of disease greater than 10 years.
These findings would seem to indicate that reversi- $\overline{\mathbb{D}}$ bility of the reflex bears some relation to total severity of the disease. Such interpretations must $\stackrel{\text { S }}{\subseteq}$ remain strictly tentative, however, owing to the sizea of our sample.

TABLE I

RESPONSE OF GLABELLAR REFLEX TO L-DOPA

\begin{tabular}{|c|c|c|c|c|c|c|}
\hline Patient & Age & $\begin{array}{c}\text { Duration } \\
\text { of } \\
\text { illness }(y r)\end{array}$ & Stage* & $\begin{array}{c}\text { Duration } \\
(y r) \text { in } \\
\text { stage } \\
I V+V\end{array}$ & $\begin{array}{l}\text { Glabellar } \\
\text { reflex } \\
\text { after } \\
\text { L-dopa }\end{array}$ & Response \\
\hline 1 & 55 & 6 & III & N.A. & Absent & Good \\
\hline 2 & 53 & 10 & III & N.A. & Absent & Good \\
\hline 3 & 66 & 4 & III & N.A. & Present & Good \\
\hline 4 & 50 & 6 & III & N.A. & Absent & Fair \\
\hline 5 & 33 & 4 & IV & N.A. & Present & Good \\
\hline 6 & 71 & 10 & V & 2 & Present & Fair \\
\hline 7 & 58 & 8 & III & N.A. & Absent & Good \\
\hline 8 & 61 & 4 & IV & 1 & Absent & Good \\
\hline 9 & 67 & 3 & III & N.A. & Absent & Good \\
\hline 10 & 62 & 15 & V & 3 & Present & Minimal \\
\hline 11 & 82 & 10 & IV & 2 & Present & Fair \\
\hline 12 & 59 & 5 & III & N.A. & Absent & Good \\
\hline 13 & 64 & 8 & V & 2 & Present & Good \\
\hline 14 & 68 & 11 & IV & 3 & Present & Good \\
\hline 15 & 74 & 14 & V & 4 & Present & Minimat \\
\hline 16 & 63 & 4 & III & N.A. & Absent & Good \\
\hline
\end{tabular}

TABLE II

RELATION OF REVERSAL OF GLABELLAR SIGN TO STAGE DISEASE

\begin{tabular}{ccccc}
\hline Stage* & Persistent & $\begin{array}{c}\text { Reversed } \\
(\text { no. })\end{array}$ & $\begin{array}{c}\text { Reversed } \\
(\%)\end{array}$ & $\begin{array}{c}0 \\
\text { III }\end{array}$ \\
IV & 2 & 7 & $78 \cdot 0$ & $\vdots$ \\
V & 2 & 1 & 33.0 & 0 \\
\hline
\end{tabular}

*Stages refer to scheme of Hoehn and Yahr (1967).

TABLE III

RELATION OF REVERSAL OF GLABELLAR SIGN TO DURATION OF DISEASE

\begin{tabular}{ccccc}
\hline $\begin{array}{c}\text { Duration } \\
\text { of disease } \\
(y r)\end{array}$ & $\begin{array}{c}\text { Patients } \\
(\text { no. })\end{array}$ & Persistent & $\begin{array}{c}\text { Reversed } \\
(\text { no. })\end{array}$ & $\begin{array}{c}\text { Reversed } \\
(\%)\end{array}$ \\
\hline $0-4$ & 5 & 2 & 3 & 60.0 \\
$5-9$ & 5 & 1 & 4 & 80.0 \\
10 or more & 6 & 5 & 1 & 16.7 \\
\hline
\end{tabular}

TABLE IV

RELATION OF REVERSAL OF GLABELLAR SIGN TO OVERALLO RESPONSE TO L-DOPA*

\begin{tabular}{|c|c|c|c|c|}
\hline Response & $\begin{array}{l}\text { Patients } \\
\text { (no.) }\end{array}$ & Persistent & $\begin{array}{c}\text { Reversed } \\
\text { (no.) }\end{array}$ & $\begin{array}{c}\text { Reversed } \\
(\%)\end{array}$ \\
\hline $\begin{array}{c}\text { Good } \\
\text { Fair } \\
\text { Minimal }\end{array}$ & $\begin{array}{r}12 \\
2 \\
2\end{array}$ & $\begin{array}{l}4 \\
2 \\
2\end{array}$ & $\begin{array}{l}8 \\
0 \\
0\end{array}$ & $\begin{array}{c}66 \cdot 7 \\
0 \\
0\end{array}$ \\
\hline
\end{tabular}

*See 'Materials and Methods' for description of clinical responsen categories. 
Of greater significance is the fact that, overall, the reflex reverted to normal in $50 \%$ of the patients and that reversal correlated highly with clinical response to L-dopa (see Table IV). All of the reflex reversals occurred in patients who were judged to have a good clinical response. The four nonreverting patients in the good clinical response category had been in stage IV or V of the disease for more than one year.

Also of interest is the fact that in the total series four of the eight patients who did not revert to the unsustained glabellar response and all of the four who showed only minimal reversion had neurological complications outside the pure syndrome of Parkinsonism. Cases 6 and 11 showed definite clinical signs of organic dementia and cases 10 and 14 had undergone bilateral thalamotomy in the past.

Of the patients in whom the glabellar reflex was reversed by L-dopa, all have remaining evidence of Parkinsonism. In patient no. 2 the first clinical change after institution of L-dopa therapy was reversal of the glabellar reflex. On the other hand, several of the patients in whom the reflex persists showed good clinical response to L-dopa (patient nos. $3,5,13,14)$.

\section{DISCUSSION}

Kugelberg (1952) and later Rushworth (1962) using EMG techniques in normal subjects and in patients with various neurological disorders have delineated the physiology of the glabellar reflex. In Kugelberg's series (1952) it was shown that both components of the glabellar reflex have roughly the same threshold. Each, however, could be elicited separately by variation of stimulus modality and strength. If the glabellar tap were made light enough, the response consisted of the first component ipsilaterally and no response contralaterally. Using a very sharp pin or a gust of air on the forehead, Kugelberg was able to elicit the second component alone, but only as a bilateral response. These latter stimuli were calculated to eliminate mechanical distortion of the muscle from the eliciting manoeuvre.

The work of Rushworth (1962) supports that of Kugelberg in that the reflex was resolved electromyographically into an early synchronous component consistent with a monosynaptic, proprioceptive response and a later asynchronous component with features of a multisynaptic nociceptive type reflex.

When repeated stimuli of fixed strength and frequency were applied to normal subjects the blink response was unsustained clinically. Electromyographically, the second component rapidly 'habituated' with a fall in amplitude and an increase in latency, while the first component retained a fixed amplitude and latency. The same stimuli applied to Parkinsonian patients resulted in a large first component with abnormally long duration; in cases of hemi-Parkinsonism the first component was larger in amplitude on the involved side. More interesting perhaps was the fact that in Parkinsonian patients the second component did not habituate as in normal subjects, but retained its amplitude and original latency indefinitely (up to 100 stimuli). In cases of hemiparesis, on the other hand, Rushworth found that the first component was large in amplitude and abnormally long in duration, while the second component habituated as in normal subjects. These findings seem consistent with the theory that both proprioceptive and avoidance (nociceptive) reactions are enhanced in Parkinson's disease, while only proprioceptive responses are affected in hemispheral disease causing hemiparesis.

It is generally agreed that the most important pathological change in Parkinsonism is degeneration of the substantia nigra (Greenfield, 1958). This lesion may be less severe in idiopathic Parkinsonism than in post-encephalitic Parkinsonism but it is characteristic of both states (Greenfield and Bosanquet, 1953). Chemically, the lesion is characterized by loss of dopamine from the substantia nigra and from the normally dopamine-rich striatum (Ehringer and Horneykiewicz, 1960). Catecholamine fluorescence has been demonstrated within the neuronal cell bodies of the substantia nigra (Dahlström and Fuxe, 1964) but no such dopamine containing neurones can be seen in the striatum using conventional light microscopic techniques (Carlsson, Falck, and Hillarp, 1962). This is despite the fact that the striatum contains the highest concentration of dopamine in the brain (Sano, Gamo, Kakimoto, Taniguchi, Takesada, and Nishinuma, 1959). Using specialized techniques the striatal dopamine was subsequently shown to exist within a dense meshwork of very fine nerve terminals in the striatum (Dahlström and Fuxe, 1965).

These observations have led to the concept of a nigrostriatal dopamine containing pathway. Andén, Carlsson, Dahlström, Fuxe, Hillarp, and Larsson (1964) have shown that experimental lesions in the substantia nigra of rats lead to loss of dopamine from the ipsilateral striatum. These investigators have also demonstrated that, within the first few days after ablation of the striatum, there is increased catechol fluorescence in the neuronal cell bodies of the ipsilateral substantia nigra (Anden, Dahlström, Fuxe, Larsson, 1965). When the animals were killed three to four weeks after placement of the same lesion, these workers observed marked loss of fluorescence along with degenerative changes in these same neurone cell bodies, especially in the pars compacta 
of the substantia nigra. These findings were felt to support the theory of a nigro-striatal tract made up of dopaminergic neurones with cell bodies in the substantia nigra and fine axon terminals forming a dense meshwork within the ipsilateral striatum. Observations concerning this pathway have been made in primates by Poirier and Sourkes (1965) and Poirier, Sourkes, Bouvier, Bouchet, and Carabin (1966). These workers reported marked cell loss in the substantia nigra along with reduced dopamine levels in the striatum after interruption of the nigrostriatal pathway by lesions placed in the pars compacta of the ipsilateral substantia nigra.

Dopamine acts as an inhibitory neurotransmitter in most species (Horneykiewicz, 1966). Of greater significance, however, is the demonstration that dopamine has an inhibitory effect on the neurones of the mammalian caudate nucleus (McLennan and York, 1967).

The therapy of Parkinsonism with L-dopa presupposes that L-dopa is converted to dopamine, which then acts at the dopamine receptor sites within the brain (Klawans, 1968). Chronic oral L-dopa therapy results in increased levels of both dopamine and homovanillic acid, the major catabolic product of dopamine, in spinal fluid of Parkinsonian patients (Klawans and Weber, 1969; Weiner, Harrison, and Klawans, 1969). The simultaneous elevation of both dopamine and homovanillic acid in the CSF of patients receiving L-dopa demonstrates that such therapy does in fact increase dopamine synthesis and concentration within the blood brain barrier. The increased amounts of dopamine can then reinstate the normal dopaminergic influence of the nigral neurones on the striatum. It is our contention that dopaminergic nigrostriatal pathways normally play a role in suppression of at least the nociceptive portion of the glabellar response and perhaps the proprioceptive portion as well. The lack of habituation in the nociceptive component of the response observed by Rushworth (1962) in Parkinsonian patients, together with the pathology of the disease would suggest that in these patients the primitive glabellar reflex has been released from the inhibitory influence of the striatum. Reversal of the sustained glabellar reflex in $50 \%$ of our Parkinsonian patients receiving L-dopa lends support to this hypothesis.

The reversal of the glabellar reflex by L-dopa in these patients is of theoretical importance. It is the first reported instance in which a reflex resulting from structural changes within the brain can be reversed by pharmacological means. This would appear to exemplify not only reinstatement of central inhibition, but, more specifically, inhibition of striatal neurones.
Despite the consistent basal ganglia abnormalities in Parkinson's disease the contribution of cortical pathology to the syndrome has not been ruled out. \& Adams, Van Bogaert, and Vander Eecken (1964) have noted that neuronal loss in the cortex with re- 0 active gliosis may be more characteristic of Parkinson's disease than has been recognized in the past. In a series of 250 Parkinsonian patients who were $\stackrel{0}{\overrightarrow{0}}$ subjected to pneumoencephalography as a prelimin- $\underset{ }{\gtrless}$ ary to therapeutic stereotactic surgery, Selby $(1968) \overrightarrow{\vec{F}}$ found evidence for cortical atrophy in $57 \cdot 2 \%$. In two of our patients in whom there were overt signs $\frac{\square}{5}$ of organic dementia the glabellar reflex remained $\frac{\bar{\sigma}}{\bar{\omega}}$ exaggerated despite L-dopa therapy. Thus the $\frac{\mathbb{\Phi}}{\mathrm{O}}$ sustained glabellar response may also result from diffuse cortical disease as suggested by Denny- $\omega$ Brown (1956) and by Pearce et al. (1958).

\section{CONCLUSIONS}

It appears that the sustained glabella response may? be a release phenomenon resulting from either loss of the inhibitory effect of dopamine on the striatume or or from diffuse cortical dysfunction. The second 서 mechanism may also involve the basal ganglia a common final pathway. Oral therapy with L-dop which reinstates the inhibitory effect of dopamine receptor sites in the striatum of Parkinsonian patients often leads to reversal of the glabellar response to th\&t seen in normal adults. This supports the conce $\mathbb{\Phi}$ that the appearance of the abnormal reflex is relat $\overrightarrow{0}$ to loss of dopamine inhibition. The fact that L-dopt therapy failed to reverse the sustained glabellar reflex in patients with clinical evidence of organic dementia lends support to the hypothesis that the exaggerated glabellar response may also result from diffuse cortical disease. This cortically originating mechan- $\frac{}{\Phi}$ ism would not directly involve the dopamine input $\stackrel{\varrho}{\rightarrow}$ to the striatum.

\section{SUMMARY}

The effect of L-dopa therapy on the glabellar reflex in Parkinsonian patients is presented. The reflex was? reversed to a normal unsustained response in eight $\frac{\text { O }}{3}$ of the 16 patients studied. Reversal of the reflex was. seen most frequently in patients who demonstrated aO good clinical response to L-dopa. Reversal was less frequent in patients with more advanced disease and $\mathrm{O}$ in those who had had the disease longer than 10D years, The reflex was not reversible in two patients with clinical dementia and in two others who had N undergone bilateral thalamotomy. The implicationsof these findings in terms of the pathogenesis of the sustained glabellar reflex are discussed. 
Some of the L-dopa used in this study was purchased from Nutritional Biochemical Corporation, Cleveland, Ohio. The rest was generously supplied by the Norwich Pharmacal Company, Norwich, New York. This study was partially supported by grants from the Women's Auxiliary of United Parkinson Foundation, Chicago, Illinois, and Mr. Edgar N. Greenebaum, Jr., Chicago, Illinois.

\section{REFERENCES}

Adams, R. D., Van Bogaert, L., and Vander Eecken, H. (1964) Striato-nigral degzneration. J. Neuropath. exp. Neurol., 23, 584-608.

Andén, N. E., Carlsson, A., Dahlström, A., Fuxe, K., Hillarp, N.-A. and Larsson, K. (1964). Demonstration and mapping out of nigro-neostriatal dopamine neurons. Life Sci., 3, 523-530.

_- Dahlström, A., Fuxe, K., and Larsson, K. (1965). Further evidence for the presence of nigro-neostriatal dopamine neurons in the rat. Amer. J. Anat., 116, 329-333.

Carlsson, A., Falck, B., and Hillarp, N. - $\AA$. (1952). Cellular localization of brain monoaminzs. Acta physiol. scand., 56, Suppl. 196

Dahlström, A., and Fuxe, K. (1954). Evidence for the existence of monoamine containing neurons in the CNS. I. Demonstration of monoamines in the cell bodies of brain stem neurons. Ibid., 62, Suppl. 232.

_ and - (1965). Evidence for the existence of monamine neurons in the central nervous system. IV. Distribution of monamine nerve terminals in the CNS. Ibid., 64, Suppl. 247.

Denny-Brown, D. (1956). Positive and negative aspects of cerebral cortical functions. N.C. med. J., 17, 295-303.

- (1960). Statement on exaggerated proprioceptive and avoidance reflexes in basal ganglia disease. Lancet, 2, 1099; 1155

- - and Chambers, R. A. (1958). The parietal lobe and behavior Res. Publ. Ass, nerv. ment. Dis., 36, 35-117.
Ehringer, H., and Horneykiewicz, O. (1960). Verteilung von Noradrenalin und Dopamin (3-hydroxytyramin) im Gehirn des Menschen und ihr Verhalten bei Erkrankungen des extrapyramidalen Systems. Klin. Wschr., 38, 1236-1239.

Greenfield, J. G. (1958). Textbook of Neuropathology. Edward Arnold: London.

Hoehn, M. M., and Yahr, M. D. (1967). Parkinsonism: onset, progression amd mortality. Neurology (Minneap.), 17, 427-424.

Horneykiewicz, O. (1966). Dopamine and brain function. Pharmacol. Rev., 18, 925-964.

Klawans H. L. (1968). Pharmacology of Parkinsonism. A review. Dis. nerv. Syst., 29, 805-816.

—_, and Weber, B. (1959). L-dopa and spinal fluid dopamine in parkinsonism. Submitted for publication.

Kugelbərg, E. (1952). Facial reflexes. Brain, 75, 385-396.

McLennan, H., and York, D. H. (1967). The action of dopamine on neurons of the caudate nucleus. J. Physiol. (Lond.), 189, 393-402.

Overend, W. (1896). Preliminary note on a new cranial reflex. Lancet, 1, 619 .

Pearce, J., Aziz, H., and Gallagher, J. C. (1968). Primitive reflex activity in primary and symptomatic Parkinsonism. J. Neurol. Neurosurg. Psychiat., 31, 501-508.

Poirier, L. J., and Sourkes, T. L. (1965). Influence of the substantia nigra on the catecholamine content of the striatum. Brain, 88 , 181-192.

_- Bouvier, G., Bouchet, R., and Carabin, S. (1966). Striatal amines, experimental tremor and the effect of harmaline in the monkey. Ibid., 89, 37-52.

Rushworth, G. (1962). Observations on blink reflexes. J. Neurol. Neurosurg. Psychiat., 25, 93-108.

Sano, I., Gamo, T., Kakimoto, Y., Taniguchi, K., Takesada, M., and Nishinuma, K. (1959). Distribution of catechol compounds in human brain. Biochim. biophys. Acta (Amst.), 32, 586-587.

Selby, G. (1968). Cerebral atrophy in Parkinsonism. J. neurol. Sci., 6 517-559.

Wartenberg, R. (1945). The Examination of Reflexes. Yearbook Publishers: Chicago, Ill.

Weiner, W., Harrison, W., and Klawans, H. L. (1969). L-dopa and cerebrospinal fluid homovanillic acid in Parkinsonism. Submitted for publication. 